\title{
Influencia de la Peroxidación de Lípidos sobre el Daño Oxidativo Mitocondrial y la Integridad de Saccharomyces cerevisiae
}

\author{
Christian Cortés-Rojo, Mirella Estrada-Villagómez, Salvador Manzo-Ávalos y Alfredo \\ Saavedra-Molina* \\ Univ. Michoacana de San Nicolás de Hidalgo, Instituto de Investigaciones Químico-Biológicas, \\ Edificio B-3, Ciudad Universitaria, 58030 Morelia, Michoacán-México (e-mail: saavedra@umich.mx)
}

*autor a quien debe ser dirigida la correspondencia

\section{Resumen}

Se ha estudiado la influencia de la peroxidación de lípidos sobre el daño oxidativo mitocondrial y la integridad de Saccharomyces cerevisiae. Para esto, se aumentó el grado de insaturación de las membranas celulares de $S$. cerevisiae con ácido a-linolénico (C18:3). Se obtuvieron esferoplastos para poder estudiar la función mitocondrial in situ. Se encontró que la peroxidación de lípidos, estimulada por la adición de $\mathrm{Fe}^{2+}$, incrementó únicamente en esferoplastos con C18:3, mientras que la función mitocondrial, medida como el consumo de oxígeno sensible a cianuro y la integridad celular, determinada por la exclusión del colorante azul de tripano, se ven afectadas de manera significativa sólo en esferoplastos con C18:3. Estos resultados muestran que la peroxidación de lípidos sensibiliza la integridad celular y la función mitocondrial hacia los daños por el estrés oxidativo.

\section{Influence of Lipoperoxidation over Mitochondrial Oxidative Damage and Integrity of Saccharomyces cerevisiae}

\begin{abstract}
The influence of lipoperoxidation over mitochondrial oxidative damage and integrity of Saccharomyces cerevisiae has been studied. For this, the unsaturation degree of cell membranes from Saccharomyces cerevisiae was increased by adding $\alpha$-linolenic acid (C18:3). Spheroplasts were obtained to evaluate in situ the mitochondrial function. Lipid peroxidation levels, stimulated by the treatment with $\mathrm{Fe}^{2+}$, increased only in spheroplasts with $\mathrm{C} 18: 3$, while mitochondrial function, measured as cyanide-sensitive oxygen consumption, and cell integrity, determined by trypan blue exclusion, were affected significatively only in spheroplasts with C18:3. These results show that lipid peroxidation sensitizes cell integrity and mitochondrial function towards damaging effects of oxidative stress.
\end{abstract}

Keywords: Saccharomyces cerevisiae, oxidative stress, linolenic acid, lipid peroxidation 


\section{INTRODUCCIÓN}

La cadena de transporte de electrones (CTE) de la mitocondria es el principal sitio de generación de especies reactivas del oxígeno (ERO) en las células aerobias eucariontes (Beckman y Ames, 1998). Diversos factores tales como la presencia de inhibidores del transporte de electrones, aumentos en la concentración mitocondrial de calcio y de metales de transición, defectos genéticos de las proteínas que constituyen la CTE, entre otros, pueden generar una condición de estrés oxidativo en donde la producción de ERO sobrepasa la capacidad antioxidante de la célula (Halliwell et al., 1992).

Durante el estrés oxidativo, uno de los principales blancos de daño oxidativo por ERO son las colas hidrofóbicas insaturadas que componen a los lípidos de las membranas mitocondriales. Por ejemplo, en partículas submitocondriales de corazón de bovino (Forsmark-Andreé et al., 1997) y en sinaptosomas de rata (Cardoso et al., 1999), el estrés oxidativo inducido por la generación de radical hidroxilo favorece la peroxidación de lípidos de membrana produciéndose una disminución en el contenido de ubiquinona, lo que limita tanto el flujo de electrones entre los complejos I, II y III así como sus actividades catalíticas. Asimismo, los complejos I y III de mitocondrias de corazón de rata sujeto a un proceso de isquemia-reperfusión, sufren una disminución en su actividad asociada con una disminución en el contenido de cardiolipina, por lo que los daños en estos complejos son atribuidos a la oxidación de este fosfolípido (Paradies et al., 2002; Petrosillo et al., 2003). Por lo tanto, la peroxidación de las membranas mitocondriales afecta a los componentes proteicos de la CTE que se encuentran embebidos en ellas, lo cual podría inhibir algunos procesos esenciales que dependen del funcionamiento de la CTE tales como la síntesis de ATP, el transporte de metabolitos e iones o el bombeo de protones (Nicholls y Ferguson, 2002), provocando como resultado final el colapso de la célula.

La susceptibilidad de las membranas biológicas a la peroxidación depende fuertemente del grado de insaturación de los lípidos que las constituyen, siendo mayor su susceptibilidad conforme aumenta el número de dobles enlaces (Pamplona et al., 2000). De acuerdo a lo anterior, la vulnerabilidad de la CTE a la inhibición por el ataque de ERO podría ser atenuada al disminuir el grado de insaturación de los ácidos grasos de las membranas lipídicas. Asimismo, la preservación de la funcionalidad mitocondrial durante el estrés oxidativo se podría traducir en una mayor capacidad de la célula para sobrevivir a los efectos nocivos del estrés oxidativo.

El objetivo de este trabajo fue comprobar esta hipótesis para lo cual se utilizaron células de la levadura Saccharomyces cerevisiae como modelo de estudio debido a que 1) la función de la CTE puede ser estudiada in situ mediante la formación de esferoplastos (células sin pared celular), 2) el grado de insaturación de sus membranas puede ser fácilmente manipulado a través de la adición de ácidos grasos insaturados libres al medio de cultivo y 3) que la composición nativa de los ácidos grasos de membrana de la levadura consiste principalmente de los ácidos grasos saturados ácido palmítico (C16:0), ácido esteárico (C18:0) y los ácidos grasos monoinsaturados ácido palmitoleico (C16:1) y ácido oleico (C18:1) (Bossie y Martin, 1989), los cuales son resistentes a la peroxidación (Holman, 1954) y permite estudiar los efectos del estrés oxidativo que son independientes de este proceso.

\section{MATERIALES Y MÉTODOS}

\section{Reactivos}

Los reactivos utilizados fueron de grado analítico, adquiridos de Sigma Chemical (St. Louis, MO. E.U.A.), excepto por la Zymoliasa 20T, que fue adquirida de ICN Biomedicals. Inc (Aurora, $\mathrm{OH}$. E.U.A.) y el sulfato ferroso 7-hidrato, de J.T. Baker.

\section{Aislamiento de esferoplastos}

Los esferoplastos se aislaron de acuerdo con el método reportado por Guérin et al. (1979), a partir de la cepa industrial Yeast Foam de la levadura S. cerevisiae. Las células fueron crecidas en medio YLac (ácido láctico 2\%, extracto de levadura 1\%, $\mathrm{KH}_{2} \mathrm{PO}_{4} 1 \%, \mathrm{NaOH} 0.5 \%,\left(\mathrm{NH}_{4}\right)_{2} \mathrm{SO}_{4} 0.12 \%, \mathrm{pH}$ 
5.0) durante $24 \mathrm{hrs}$. a $30^{\circ} \mathrm{C}$ y $150 \mathrm{rpm}$. A las $24 \mathrm{hrs}$ se re-sembró en medio YLac fresco a una densidad óptica (DO) de 0.03 a $600 \mathrm{~nm}$ y las células fueron cosechadas en fase de crecimiento exponencial tardía ( $D O=3.5-4.0)$. Las levaduras se lavaron 3 veces por centrifugación con agua destilada a $2744 \mathrm{~g}$, se resuspendieron en medio $\mathrm{SH}$ (Tris $0.1 \mathrm{M}, \beta$-mercaptoetanol $0.5 \mathrm{M}, \mathrm{pH} 9.3$ con $\mathrm{NaOH}$ ) y se dejaron incubar a $32^{\circ} \mathrm{C}$ durante 15 minutos. Posteriormente, las células fueron lavadas 2 veces por centrifugación a $2744 \mathrm{~g}$ con medio de lavado $(\mathrm{KCl} 0.5 \mathrm{M}$, tris $10 \mathrm{mM}, \mathrm{pH} 7$ con $\mathrm{HCl})$. Para la obtención de los esferoplastos, las células se resuspendieron en medio de digestión (sorbitol 1.35 M, EGTA $1 \mathrm{mM}$, fosfato disódico $30 \mathrm{mM}$, fosfato monosódico $30 \mathrm{mM}$, ácido cítrico $10 \mathrm{mM}$, pH 5.8) y se agregó la enzima zymoliasa 20T a razón de $10 \mathrm{mg}$ por cada gramo de peso seco. La formación de esferoplastos se evaluó midiendo la disminución de la DO a $600 \mathrm{~nm}$. La incubación con la zymoliasa se detuvo en el momento en que la DO de una dilución de las células con agua 1:100 fue igual a la DO de una dilución 1:1000 determinada al inicio de la incubación. Por ultimo, los esferoplastos fueron lavados 3 veces con buffer de lavado de protoplastos (sorbitol $0.75 \mathrm{M}$, manitol $0.4 \mathrm{M}$, Tris-maléico 10 $\mathrm{mM}$, albúmina sérica de bovino $0.2 \%, \mathrm{pH} 6.8$ ) a $686 \mathrm{~g}$ por 5 minutos y resuspendidos en el mismo medio. La concentración de proteína fue determinada por el método de Biuret modificado (Gornall et al., 1949) utilizando como estándar albúmina bovina sérica.

\section{Manipulación del contenido de ácidos grasos de la levadura}

La composición de ácidos grasos de S. cerevisiae se manipuló con el método modificado de Bossie y Martin (1989), mediante la adición de $1 \mathrm{mM}$ de ácido a-linolénico (ácido cis,cis,cis-9,12,15octadecatrienoico, $\alpha-C 18: 3^{9,12,15}$, pureza $\geq 99 \%$, adquirido de Sigma Chemical) disuelto en IGEPAL CA-630 a un cultivo de $S$. cerevisiae en medio YLac $(D O=0.03$ a $600 \mathrm{~nm})$, el cual se incubó como se describió anteriormente.

\section{Extracción y análisis de lípidos}

Los lípidos fueron extraídos por el método reportado por Bligh y Dyer (1959). Las células fueron resuspendidas en agua destilada $(1 \mathrm{ml})$ y se adicionó $3.75 \mathrm{ml}$ de una mezcla cloroformo:metanol 1:2 $(\mathrm{v} / \mathrm{v})$. Esta mezcla fue homogenizada vigorosamente con un vástago de teflon. Después, se agregó $1.25 \mathrm{ml}$ de cloroformo y $1.25 \mathrm{ml}$ de agua y se agitó vigorosamente después de cada adición. Por último, se centrifugó durante $5 \mathrm{~min}$. a $2744 \mathrm{~g}$ y la fase orgánica se extrajo con una pipeta Pasteur. Para el análisis de los ácidos grasos, los respectivos metil-ésteres se prepararon por el método descrito por Morrison y Smith (1964). Brevemente, los lípidos fueron combinados con trifluoruro de boro $\left(\mathrm{BF}_{3}\right)$ al $14 \%$ en metanol durante $30 \mathrm{~min}$. a $92^{\circ} \mathrm{C}$ en baño de agua. A continuación, la muestra se enfrió a temperatura ambiente y los metil ésteres se extrajeron por agitación vigorosa con dos volúmenes de n-hexano. Después de la adición de un volumen de agua, se formó un sistema de dos fases que se centrifugó y se colectó la fase orgánica. Se evaporó el n-hexano bajo una corriente de nitrógeno y los ácidos grasos transesterificados se resuspendieron en n-hexano para su posterior análisis. Los metil ésteres se analizaron en un cromatógrafo de gases Perkin Elmer Clarus 500 controlado por computadora, equipado con un inyector capilar "split/splitless" y detector de ionización de llama. La separación se realizó en una columna capilar Omegawax (0.25 mm de diámetro interno) de 30 metros de longitud. Se utilizó nitrógeno de alta pureza como gas de acarreo. Se determinaron los tiempos de retención de cada uno de los estándares de metil-ésteres de ácidos grasos y se hicieron curvas de calibración para cada uno de ellos. La composición de ácidos grasos y su concentración se determinaron por comparación de los tiempos de retención y por análisis de las áreas bajo los picos, respectivamente.

\section{Inducción de estrés oxidativo}

Se establecieron condiciones de estrés oxidativo incubando los esferoplastos a razón de $0.3 \mathrm{mg} / \mathrm{ml}$ de proteína en medio de incubación de fosfatos $\left(\mathrm{Na}_{2} \mathrm{HPO}_{4} 0.5 \mathrm{M}, \mathrm{MgSO}_{4} 2 \mathrm{mM}, \mathrm{KH}_{2} \mathrm{PO}_{4} 10 \mathrm{mM}\right.$, EGTA $0.5 \mathrm{mM}$, a pH 6.8) con concentraciones de 50, y $100 \mu \mathrm{M}$ de $\mathrm{FeSO}_{4}$ durante 30 minutos a una temperatura de $4^{\circ} \mathrm{C}$. El hierro en estado reducido $\left(\mathrm{Fe}^{2+}\right)$, adicionado en células intactas suspendidas en solución amortiguadora de fosfatos, puede estimular la formación de radical hidroxilo, el cual es capaz de iniciar el proceso de peroxidación de lípidos, así como propagar dicho proceso mediante la 
reacción del $\mathrm{Fe}^{2+}$ con los lipoperóxidos generados por la auto-oxidación de los radicales lipídicos para generar radicales alcoxilo (North et al., 1992).

\section{Medición del consumo de oxígeno}

Al término de la inducción del estrés oxidativo, los esferoplastos $(3 \mathrm{ml})$ fueron transferidos a una cámara de vidrio sellada y la velocidad de consumo de oxígeno (respiración) de los esferoplastos fue determinada a temperatura ambiente con un electrodo tipo Clark acoplado a un monitor biológico de oxígeno YSI 5300 y a un graficador. La respiración basal (estado 4) fue inducida mediante la adición de $5 \mu \mathrm{l}$ de etanol como sustrato respiratorio. La adición de un agente protonóforo abate el potencial de membrana generado a través de la membrana interna de la mitocondria debido al bombeo de protones hacia el espacio intermembranal por los complejos de la CTE (Nicholls y Ferguson, 2002). Esto causa que la actividad de la cadena respiratoria se estimule al máximo para restablecer el potencial transmembranal; a esta condición se le denomina estado desacoplado (estado D) y permite estudiar la actividad máxima de la CTE. Para tal efecto, se agregó $5 \mu \mathrm{M}$ del desacoplante carbonilcianuro-p-trifluorometoxifenilhidrazona (FCCP). La respiración fue inhibida en su totalidad por la adición de $500 \mu \mathrm{M}$ de $\mathrm{KCN}$, indicando que la medición de dicho parámetro refleja exclusivamente la actividad de la CTE y descarta la medición artificial del consumo de oxígeno producto de la actividad redox del ion $\mathrm{Fe}^{2+}$ y sus derivados.

\section{Medición de los niveles de peroxidación lipídica}

Los niveles de peroxidación lipídica fueron determinados mediante una modificación del método del acido tiobarbitúrico (TBA) reportada por Buege y Aust (1978). Al término de la inducción del estrés oxidativo, se agregó a cada muestra $2 \mathrm{ml}$ de una solución ácida compuesta por ácido tricloroacético $15 \%$, TBA $0.375 \%$ y $\mathrm{HCl} 0.25 \mathrm{~N}$. Posteriormente, las muestras se calentaron en un baño de agua hirviendo y a los 15 minutos, fueron enfriadas en hielo y centrifugadas a $2744 \mathrm{~g}$ durante 5 minutos. Por último, se extrajo el sobrenadante y se leyó su absorbancia a $532 \mathrm{~nm}$ en un espectrofotómetro UV/vis Perkin-Elmer Lambda 18. Los resultados fueron expresados como nanomoles de sustancias reactivas al TBA (TBARS) producidas por mg. de proteína y fueron calculados en base al coeficiente de extinción molar $(\varepsilon)$ de malondialdehido de $1.56 \times 10^{5} \mathrm{M}^{-1} \mathrm{~cm}^{-1}$.

\section{Determinación de la viabilidad celular}

La viabilidad de los esferoplastos fue determinada evaluando la incorporación del colorante azul de tripano al interior de las células. El azul de tripano es un colorante cargado negativamente, por lo cual, es excluido de las células cuya membrana plasmática se encuentra íntegra, mientras que las células con la membrana plasmática dañada se tiñen de azul (Freshney, 1987). Los esferoplastos fueron tratados como se indica en inducción del estrés oxidativo, excepto que las incubaciones con los oxidantes se hicieron hasta por 7 horas. Después de cada incubación se tomó una alícuota de 25 $\mu \mathrm{l}$ y se colocó en un portaobjetos adicionando $25 \mu \mathrm{l}$ del colorante azul de tripano; la suspensión se observó al microscopio con objetivo seco fuerte y se contaron los esferoplastos viables y no viables por campo hasta 100 esferoplastos.

\section{Procesamiento estadístico}

Los resultados se expresaron como la media \pm el error estándar de al menos 5 experimentos. Los niveles de significancia $(p<0.01$ y $p<0.05)$ se determinaron mediante la prueba $t$ de Student con el programa de computadora Sigma Plot Versión 9 (SPSS Inc).

\section{RESULTADOS}

Efecto de la adición de ácido linolénico sobre el perfil de ácidos grasos

Con el objetivo de aumentar la susceptibilidad de S. cerevisiae hacia la peroxidación lipídica, las células fueron crecidas en presencia del ácido graso triinsaturado ácido a-linolénico $(C 18: 3)$ para estimular su incorporación en los lípidos de membrana y aumentar el grado de insaturación de la 
misma. Como se muestra en la figura $1 \mathrm{~A}$, la composición nativa de ácidos grasos de $\mathrm{S}$. cerevisiae consiste principalmente de los ácidos grasos monoinsaturados ácido oleico (C18:1, 40.9\%) y ácido palmitoleico $(\mathrm{C} 16: 1,23.5 \%)$ y en menor proporción de los ácidos grasos saturados ácido palmítico $(\mathrm{C} 16: 0,21.7 \%)$ y ácido oleico $(\mathrm{C} 18: 1,13.9 \%)$. Cuando las células fueron crecidas en presencia de C18:3 (Fig 1B), este ácido graso se convirtió en el principal constituyente (92.9\%), mientras que la concentración de ácidos grasos saturados C16:0 y C18:0 disminuyó a 2.9\% y 2.2\%, respectivamente. En el caso de los ácidos grasos monoinsaturados, solo se detectaron cantidades marginales $(0.72 \%$ y $1.15 \%$ de $\mathrm{C} 16: 1$ y C18:1, respectivamente).
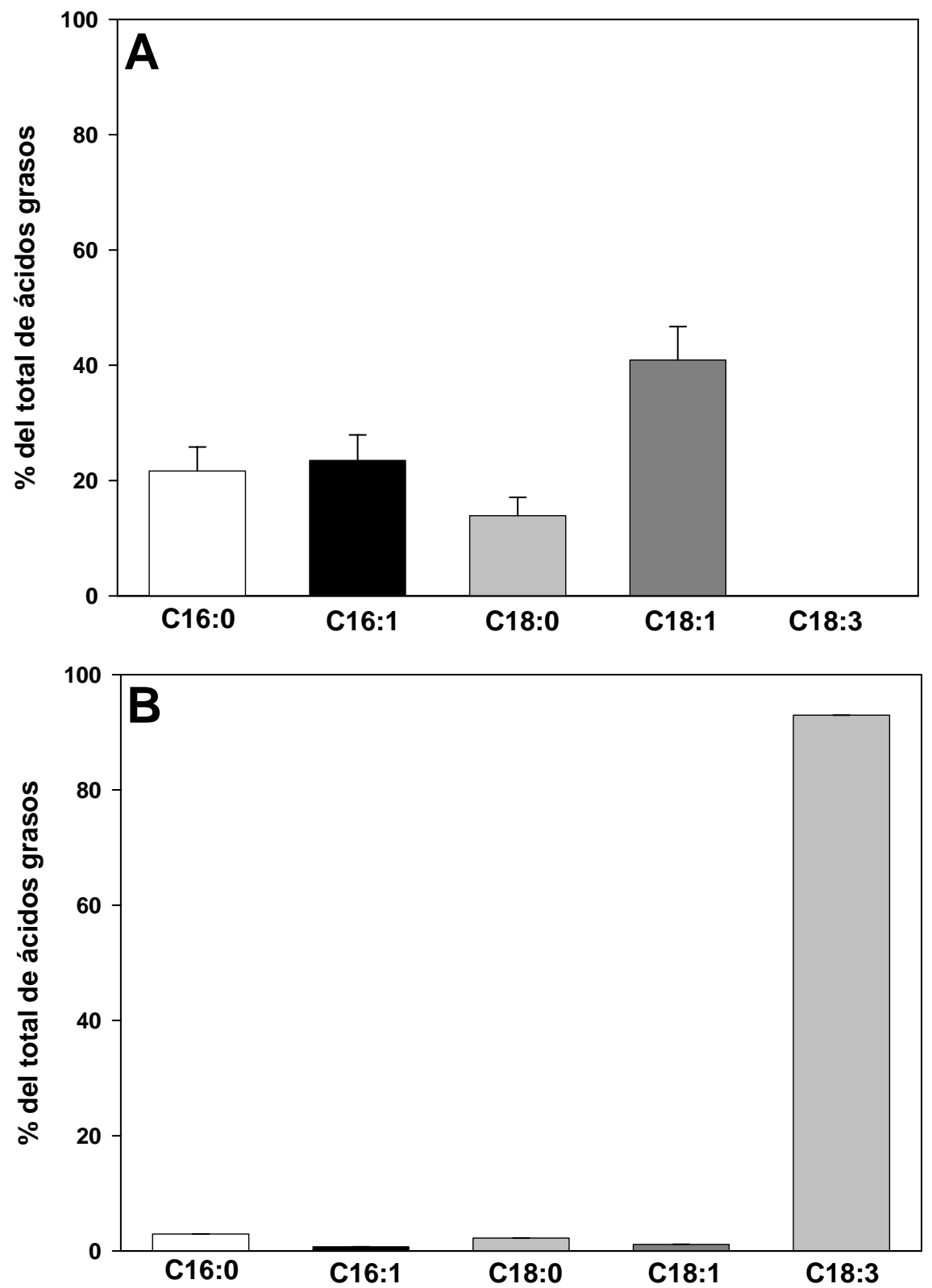

Fig. 1: Composición porcentual de ácidos grasos de la levadura crecida en ausencia (panel A) y en presencia (panel B) de $1 \mathrm{mM}$ de $\mathrm{C} 18: 3$. Los valores se expresan como el promedio \pm el error estándar de los porcentajes de cada ácido graso.

Influencia de la composición de ácidos grasos sobre los efectos del estrés oxidativo por $\mathrm{Fe}^{2+}$ en los niveles de peroxidación lipídica

Con el propósito de investigar si la incorporación de ácido linolénico sensibiliza a los lípidos de membrana de la levadura hacia los efectos dañinos del estrés oxidativo, se midieron los niveles de peroxidación lipídica en esferoplastos con y sin C18:3. En esferoplastos sin C18:3 (Fig. 2, barras 
blancas), los niveles de peroxidación se mantuvieron constantes a las dos concentraciones de $\mathrm{Fe}^{2+}$ utilizadas $(50$ y $100 \mu \mathrm{M})$. En contraste, los niveles de peroxidación de los esferoplastos con C18:3 (Fig. 2, barras negras) aumentaron un $51 \%$ y $353 \%$ con 50 y $100 \mu \mathrm{M}$ de $\mathrm{Fe}^{2+}\left({ }^{* *} \mathrm{p}<0.01\right)$, respectivamente. Estos resultados indican que el aumento en los niveles de insaturación de los ácidos grasos membranales sensibiliza a la célula hacia los efectos dañinos del estrés oxidativo.

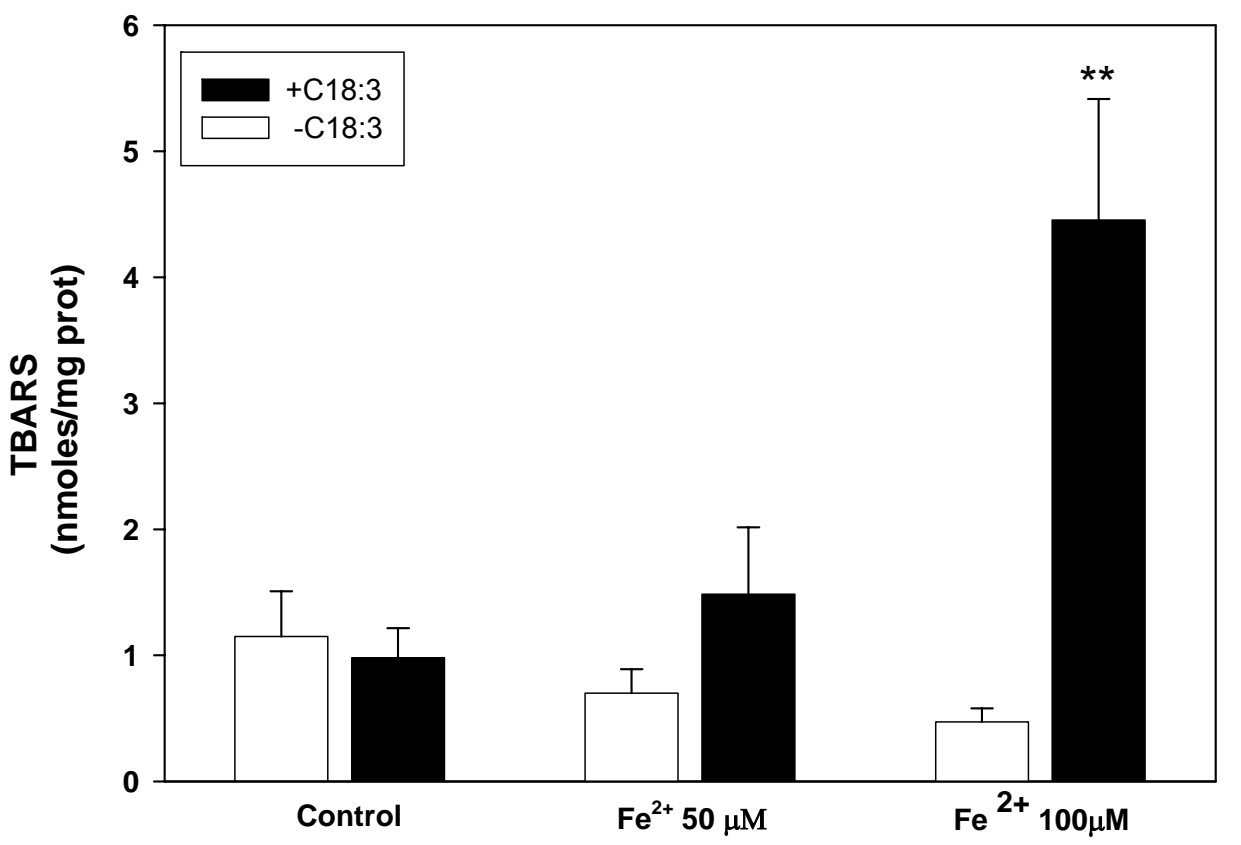

Fig. 2: Efecto del $\mathrm{Fe}^{2+}$ sobre la peroxidación lipídica en esferoplastos con (barras negras) y sin (barras blancas) C18:3. Los resultados se expresan como el promedio \pm el error estándar de las sustancias reactivas al ácido tiobarbitúrico (TBARS) $(p<0.01)$.

Influencia de la composición de ácidos grasos sobre la sensibilidad de la función mitocondrial in situ al estrés oxidativo por ion $\mathrm{Fe}^{2+}$

Con la finalidad de determinar si el aumento de la susceptibilidad a la peroxidación lipídica de la célula puede sensibilizar al mismo tiempo la funcionalidad de la CTE al estrés oxidativo, se evaluó in situ la función mitocondrial de esferoplastos de levadura midiendo el consumo de oxígeno sensible a cianuro. En esferoplastos sin C18:3 (Fig. 3, barras blancas), la respiración se encontró prácticamente inalterada tanto en estado 4 como en estado $\mathrm{D}$ bajo cualquier concentración de $\mathrm{Fe}^{2+}$ utilizada con excepción de la respiración en estado $\mathrm{D}$ a $100 \mu \mathrm{M}$ de $\mathrm{Fe}^{2+}$, donde se observó una inhibición no significativa de alrededor del $22 \%$. En contraste, la misma concentración de $\mathrm{Fe}^{2+}$ causó en esferoplastos con C18:3 (Fig. 3, barras negras) una inhibición significativa $(p<0.01)$ de de aproximadamente $53 \%$ en la respiración en estado D. Asimismo, se observaron efectos menos pronunciados en esferoplastos con $\mathrm{C} 18: 3$ en el estado $\mathrm{D}$ a $50 \mu \mathrm{M}$ de $\mathrm{Fe}^{2+}$ y en estado 4 a $100 \mu \mathrm{M}$ de $\mathrm{Fe}^{2+}(20 \%$ y $26 \%$, respectivamente). Es de resaltarse que en el estado 4 no se observó un aumento en el consumo de oxígeno tanto en esferoplastos con y $\sin \mathrm{C} 18: 3$, indicando que no se presentó un desacoplamiento aparente de la CTE debido a un aumento en la permeabilidad de la membrana interna mitocondrial, En conjunto, los resultados anteriores muestran que el aumento en la susceptibilidad a la peroxidación lipídica debido a un aumento en los niveles de insaturación de los ácidos grasos de membrana convierten a la CTE de la mitocondria en un blanco importante del estrés oxidativo.

Influencia de la composición de ácidos grasos sobre los efectos del ion $\mathrm{Fe}^{2+}$ en la viabilidad celular

Para conocer el efecto del estrés oxidativo sobre la integridad celular de la levadura y su relación con la susceptibilidad a la peroxidación lipídica, se midió la viabilidad celular a través de la incorporación del colorante azul de tripano al interior de la célula. En la figura 4 se observa que la viabilidad de los 
esferoplastos sin C18:3 tratados en presencia de $100 \mu \mathrm{M}$ de $\mathrm{Fe}^{2+}$ (Fig. 4, círculos blancos) disminuye en menos de $12 \%$ a través de todo el tiempo de incubación ( $7 \mathrm{hrs}$.) En contraste, la viabilidad de los esferoplastos con $\mathrm{C} 18: 3$ tratados con la misma concentración de $\mathrm{Fe}^{2+}$ (Fig. 4, círculos negros) disminuyó de manera más acentuada, obteniéndose una inhibición mayor al $12 \%$ a las 3 horas de incubación y un valor máximo de inhibición del $33 \%$ a las 7 horas de incubación. Un comportamiento muy parecido al anterior se observó en esferoplastos sin C18:3 tratados con una concentración de $\mathrm{Fe}^{2+} 10$ veces más alta $(1 \mathrm{mM})$ (Fig. 4, cuadros blancos). A esta concentración, la pérdida de la viabilidad fue notablemente más rápida en los esferoplastos con C18:3 (Fig. 4, cuadros negros), apreciándose una pérdida total de la misma a las $7 \mathrm{hrs}$. de incubación. Por lo tanto, los resultados anteriores indican que una menor susceptibilidad a la peroxidación de lípidos debido a un menor grado de insaturación de los mismos, protege a la célula de los efectos dañinos del estrés oxidativo inducido por $\mathrm{Fe}^{2+}$.

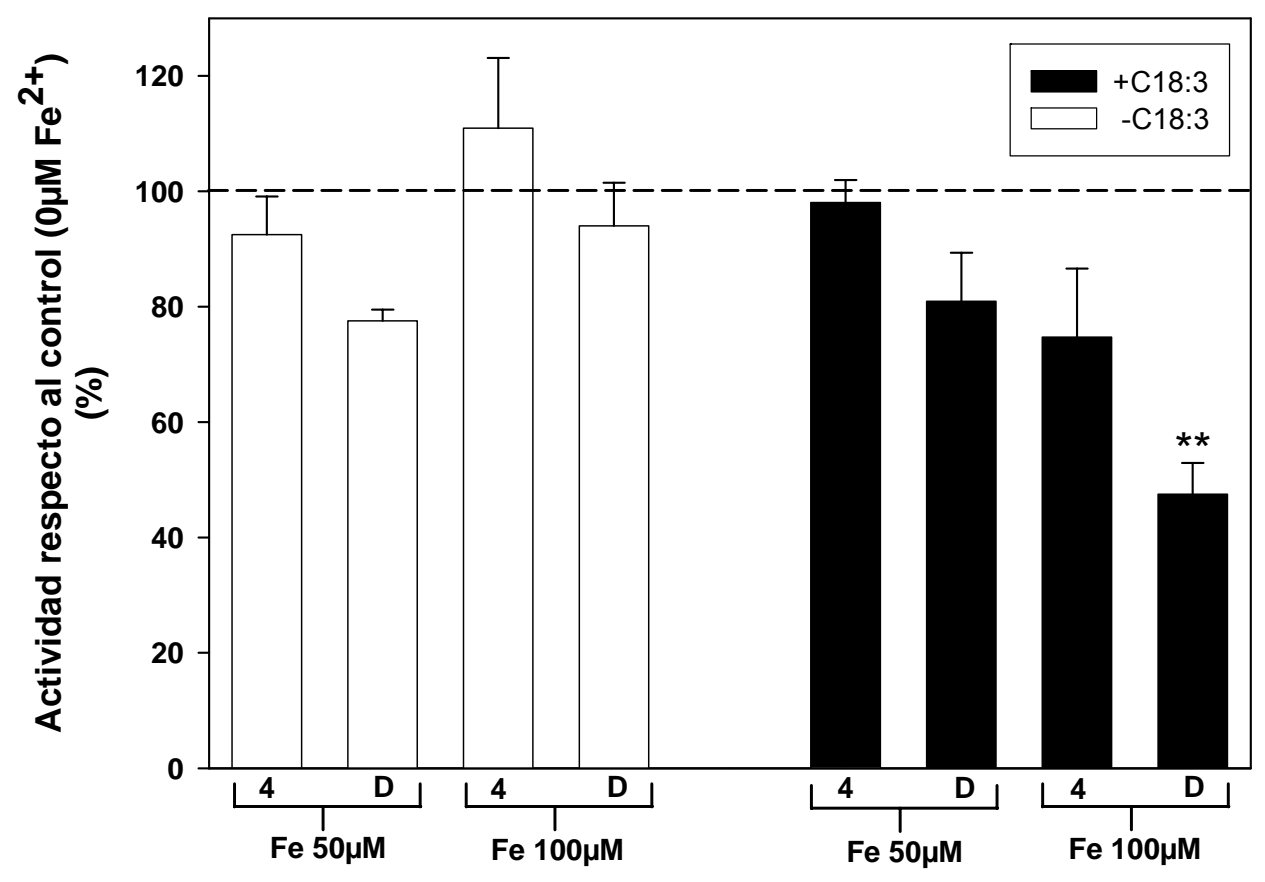

Fig. 3: Efecto del $\mathrm{Fe}^{2+}$ sobre la respiración de esferoplastos con (barras negras) y sin (barras blancas) C18:3. La respiración en estado 4 (4) y en estado desacoplado (D) se estimuló como se indica en Materiales y Métodos. Los resultados se expresan como el promedio \pm el error estándar del porcentaje de la velocidad de respiración respecto al control $\left(0 \mu \mathrm{M}\right.$ de $\left.\mathrm{Fe}^{2+}\right)(\mathrm{p}<0.01)$.

\section{DISCUSIÓN}

Los resultados de este trabajo muestran que la resistencia a la peroxidación de lípidos, evidenciada por la nula estimulación de este parámetro incluso a $100 \mu \mathrm{M}$ de $\mathrm{Fe}^{2+}$, está relacionada con una resistencia substancial de la CTE y la integridad celular hacia el daño por el estrés oxidativo. Esta resistencia disminuyó cuando las células fueron enriquecidas con C18:3.

El aumento en el grado de insaturación de los lípidos de membrana en solo 2 insaturaciones obtenido mediante la adición de C18:3, provocó diferencias dramáticas en las respuestas de los diferentes parámetros medidos ante el estrés oxidativo. Los niveles de peroxidación de lípidos obtenidos en este trabajo están en concordancia con los obtenidos en el trabajo pionero de Holman (1954) con ácidos grasos purificados, en el que se muestra que los ácidos grasos saturados y monoinsaturados de 16 y de 18 carbonos son resistentes a la peroxidación, mientras que el aumento en el grado de insaturación a partir de dos dobles enlaces incrementa la sensibilidad de los ácidos grasos hacia este proceso de una manera directamente proporcional al número de dobles enlaces 
presente. El enriquecimiento con C18:3 disminuyó de manera dramática los porcentajes de C16:1 y C18:1 de un $23.5 \%$ y $40.9 \%$ a solo 0.72 y $1.15 \%$, respectivamente. Lo anterior puede ser el reflejo de la represión que los ácidos grasos insaturados ejercen sobre la transcripción del gen OLE1 que codifica para la desaturasa $\Delta 9$ que forma el doble enlace entre los carbonos 9 y 10 del C16:0 y el C18:0; como consecuencia, la levadura remplaza las especies monoinsaturadas nativas por los ácidos grasos adicionados al medio de cultivo (Martin et al., 2007).

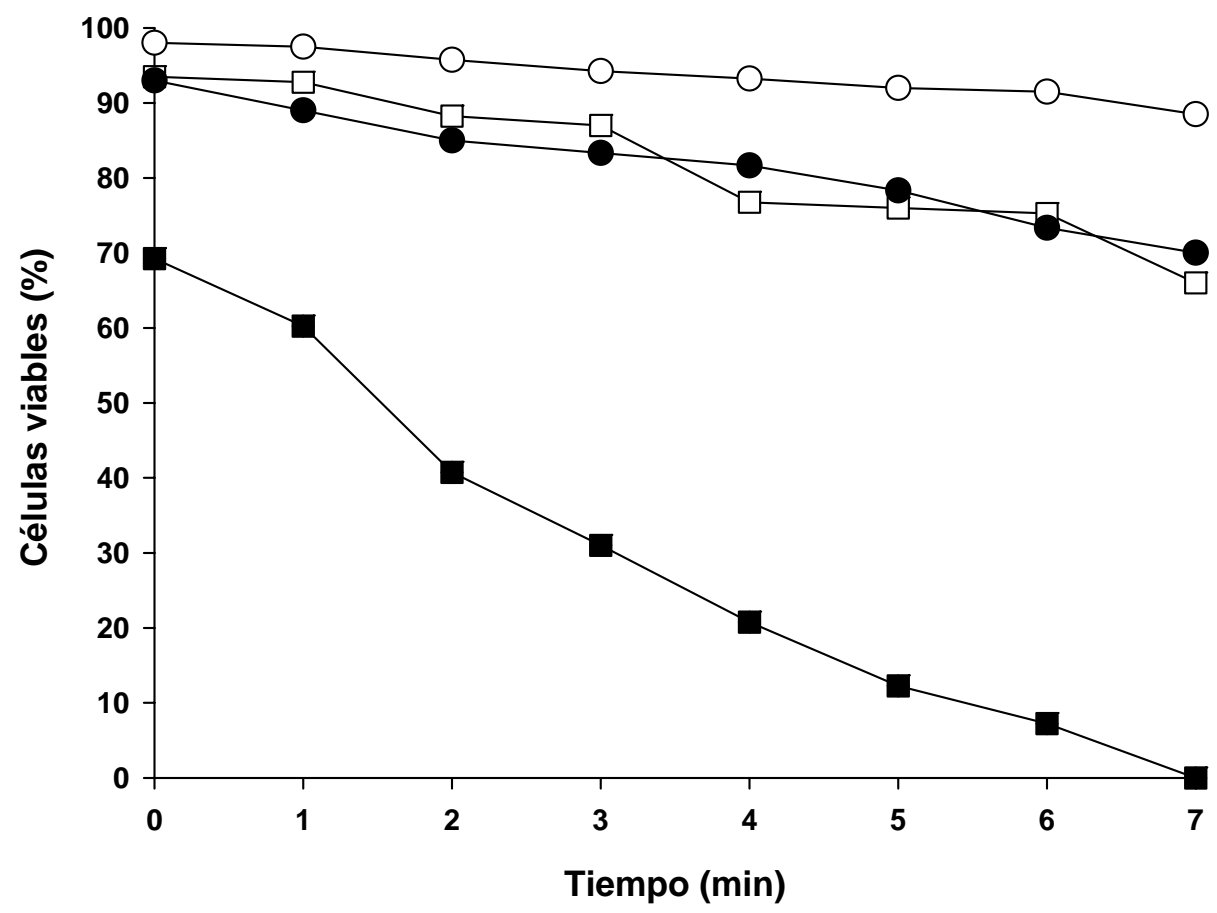

Fig. 4: Efecto del $\mathrm{Fe}^{2+}$ sobre la viabilidad de esferoplastos de S. cerevisiae. Sin (símbolos blancos) y con (símbolos negros) C18:3, tratados con $100 \mu \mathrm{M}$ (círculos) y $1000 \mu \mathrm{M}$ (cuadros) de Fe ${ }^{2+}$. Los resultados se expresan como el porcentaje de células que excluyeron el colorante azul de tripano.

Se pudo observar una buena concordancia entre los resultados de peroxidación de lípidos y la inhibición de la CTE obtenidos en esferoplastos con $\mathrm{C} 18: 3$ a $100 \mu \mathrm{M}$ de $\mathrm{Fe}^{2+}$, ya que es a esta concentración donde se observaron de manera significativa los cambios más notables en dichos parámetros. Bajo esta condición, es posible proponer dos mecanismos o la combinación de ambos que podrían explicar la inhibición en el funcionamiento de la CTE: el primero consiste en que a esta concentración de $\mathrm{Fe}^{2+}$, el daño inducido en la membrana plasmática por la peroxidación permita el paso libre del $\mathrm{Fe}^{2+}$ hacia el citosol, lo cual es apoyado por el incremento en la pérdida de viabilidad en esferoplastos con C18:3. En consecuencia, las membranas mitocondriales estarían expuestas directamente a los efectos peroxidativos de este catión afectando a los componentes de la CTE. Esta situación sería favorecida debido al hecho de que la mitocondria de la levadura transporta de manera preferencial el Fe en estado reducido proveniente del espacio intermembranal (Kwok y Kosman, 2005). Asimismo, una sobrecarga citosólica de Fe y su acumulación en la mitocondria han sido reportados en células de murino (Shvartsman et al., 2007). El otro posible escenario es que a esta concentración de $\mathrm{Fe}^{2+}$, la acumulación de MDA (4.5 nanomoles/mg prot), uno de los productos finales de la peroxidación de lípidos, sea capaz de reaccionar con los complejos proteicos de la CTE inhibiendo su actividad. El MDA puede modificar de manera covalente grupos -SH expuestos de cisteínas de los complejos de la CTE de eucariontes superiores, lo cual inhibe de manera negativa el transporte de electrones a través de la CTE (Lashin et al., 2006). Asimismo, en mitocondrias de levadura se ha encontrado que el estrés oxidativo puede regular la actividad de la CTE a nivel de los complejos II y III mediante la oxidación reversible de -SH (Cortés-Rojo et al., 2007). Por lo tanto, estos dos complejos podrían constituir el blanco de inhibición por los sub-productos de la peroxidación de lípidos. 
Independientemente del mecanismo de inhibición de la CTE, resulta evidente que el aumento en la sensibilidad a la peroxidación convierte a la mitocondria en uno de los principales blancos del estrés oxidativo y que la composición nativa de los ácidos grasos membranales le confiere por si misma una resistencia notable a la célula a los efectos dañinos del estrés oxidativo. En relación a lo anterior, existe evidencia creciente de que el grado de insaturación y la susceptibilidad a la peroxidación de los lípidos mitocondriales es uno de los principales determinantes del tiempo de vida de eucariontes superiores en diversas especies (Pamplona et al., 2000). En el caso de la levadura, se ha encontrado que la incorporación de ácidos grasos insaturados en sus membranas celulares mediante la expresión heteróloga de desaturasas provenientes de girasol (Rodríguez-Vargas et al., 2007), aumenta la resistencia de las células al estrés salino y por congelamiento. No obstante la ventaja que supone lo anterior (la conservación de las células por un tiempo prolongado para aplicaciones industriales), los resultados obtenidos en el presente estudio sugieren que la levadura con un nivel mayor de insaturación podría ser menos eficiente en algún proceso industrial donde puede presentarse la sobreproducción de ERO, tal como la producción de etanol, en donde, al menos en eucariontes superiores, se ha demostrado que el metabolismo de este alcohol puede aumentar la formación de ERO en la mitocondria mediante diferentes mecanismos (Phillips y Jenkinson, 2001; Hoek et al., 2002).

\section{CONCLUSIONES}

Se encontró que la sensibilidad de esferoplastos de S. cerevisiae hacia la peroxidación de lípidos inducida por $\mathrm{Fe}^{2+}$ es prácticamente nula, mientras que el funcionamiento de la CTE de la mitocondria y la integridad de la célula no muestran tampoco alteraciones importantes a 50 y $100 \mu \mathrm{M} \mathrm{de} \mathrm{Fe}^{2+}$. La adición de $1 \mathrm{mM}$ de $\mathrm{C} 18: 3$ provocó cambios dramáticos en la composición de ácidos grasos membranales al presentarse un enriquecimiento hasta del $90 \%$ en este ácido graso y una disminución drástica en los ácidos grasos saturados y monoinsaturados nativos de la levadura. Estos cambios sensibilizaron a las células hacia los efectos del estrés oxidativo generado por el tratamiento con $100 \mu \mathrm{M}$ de $\mathrm{Fe}^{2+}$ ya que los niveles de peroxidación de lípidos aumentaron en $353 \%$; la respiración en estado D y la viabilidad celular disminuyeron en alrededor de un $50 \%$ y $33 \%$, respectivamente, mientras que $1 \mathrm{mM}$ indujo una pérdida total de viabilidad a las $7 \mathrm{hrs}$. En conjunto, estos resultados muestran que la peroxidación de lípidos convierte a la mitocondria en un blanco importante del estrés oxidativo.

\section{AGRADECIMIENTOS}

Los autores agradecen el apoyo de los donativos: Fondos Mixtos-Gob. del Estado de Michoacán (64277, 64308), COECYT, CIC-UMSNH (2.16). CCR es becario CONACYT.

\section{REFERENCIAS}

Beckman, K.B. y B.N. Ames; The free radical theory of aging matures, Physiol. Rev: 78(2), 547581(1998).

Bligh, E.G., y W.J. Dyer; A rapid method of total lipid extraction and purification. Can. J. Biochem. Physiol: 37(8), 911-917 (1959).

Bossie, M.A. y C.E. Martin; Nutritional regulation of yeast $\Delta-9$ fatty acid desaturase activity, J. Bact: 171(12), 6409-6413 (1989).

Buege, J.A. y S.D, Aust; Microsomal lipid peroxidation, Methods Enzymol.: 52, 302-310 (1978).

Cardoso, S.M., C. Pereira, y C.R. Oliveira; Mitochondrial function is differentially affected upon oxidative stress. Free Radic. Biol. Med.: 26(1-2), 3-13 (1999).

Cortés-Rojo, C. y otros seis autores; Electron transport chain of Saccharomyces cerevisiae mitochondria is inhibited by $\mathrm{H}_{2} \mathrm{O}_{2}$ at succinate-cytochrome $c$ oxidoreductase level without lipid peroxidation involvement. Free Radic. Res.: 41(9), 1212-1223 (2007). 
Forsmark-Andreé, P., C.P. Lee, G. Dallner y L. Ernster; Lipid peroxidation and changes in the ubiquinone content and the respiratory chain enzymes of submitochondrial particles. Free Radic. Biol. Med.: 22(3), 391-400 (1997).

Freshney, R.; Culture of Animal Cells: A Manual of Basic Technique, p.117, Alan R. Liss, Inc., New York (1987).

Gornall, A.G., C.J. Bardawill y M.M. David; Determination of serum proteins by means of the Biuret reaction. J. Biol. Chem. 177(2), 751-766 (1949).

Guérin, B., P. Labbe y M. Somlo; Preparation of yeast mitochondria (Saccharomyces cerevisiae) with good P/O and respiratory control ratios. Methods Enzymol.: 55, 149-159 (1979).

Halliwell, B., J.M. Gutteridge y C.E. Cross; Free radicals, antioxidants and human disease: where are we now? J. Lab. Clin. Med: 119(6), 598-620 (1992).

Hoek, J.B., A. Cahill y J.G. Pastorino; Alcohol and mitochondria: A dysfunctional relationship. Gastroenterology: 122(7), 2049-2063 (2002).

Holman, R.T.; Autooxidation of fats and related substances. En: Holman, R.T., Lundberg, W.O., Malkin, T. (Eds). Progress in the chemistry of fats and other lipids, vol 2. Academic Press, New York, pp. 51-98 (1954).

Kwok, E. y D. Kosman, Iron in yeast: mechanisms involved in homeostasis. En Topics in Current Genetics, Molecular Biology of Metal Homeostasis: From Microbes to Man. Tamas, M.J., and Marinoia, E. (eds). Berlin: Springer-Verlag, pp. 59-99 (2005).

Lashin, O.M., P.A. Szweda, L.I. Szweda y A.M. Romani; Decreased complex II respiration and HNEmodified SDH subunit in diabetic heart. Free Radic. Biol. Med: 40(5), 886-96 (2006).

Martin, C.E., C. Oh y Y. Jiang; Regulation of long chain unsaturated fatty acid synthesis in yeast. Biochim. Biophys. Acta: 1771(3), 271-285 (2007).

Morrison, W.R. y L.M. Smith; Preparation of fatty acid methyl esters and dimethylacetals from lipids with boron fluoride-methanol. J. Lipid Res: 5(10), 600-608 (1964).

Nicholls, D.G. y S.J. Ferguson; Bioenergetics 3. London, UK Academic Press. 5, 89-156 (2002).

North, J.A., A.A. Spector y G.R. Buettner; Detection of lipids radicals by electron paramagnetic resonance spin trapping using intact cells enriched with polyunsaturated fatty acid. J. Biol. Chem.: 267(9), 5743-5746 (1992).

Pamplona, R. y otros seis autores; Low fatty acid unsaturation: a mechanism for lowered lipoperoxidative modification of tissue proteins in mammalian species with long life spans. J. Gerontol. A Biol. Sci. Med. Sci: 55(6), 286-291 (2000).

Paradies, G., G. Petrosillo, M. Pistolese y F.M. Ruggiero; Reactive oxygen species affect mitochondrial electron transport complex I activity through oxidative cardiolipin damage. Gene: 286(1), 135-141 (2002).

Petrosillo, G., F.M. Ruggiero, N. Di Vennosa y G. Paradies; Decreased complex III activity in mitochondria isolated from rat heart subjected to ischemia and reperfusion: role of reactive oxygen species and cardiolipin. FASEB J.: 17(6), 714-716 (2003).

Phillips, B.J. y P. Jenkinson; Is ethanol genotoxic? A review of the published data. Mutagenesis: 16(2), 91-101 (2001). 
Rodríguez-Vargas, S. y otros cuatro autores; Fluidization of membrane lipids enhances the tolerance of Saccharomyces cerevisiae to freezing and salt stress. Appl. Environ. Microbiol: 73(1), 110-116 (2007).

Shvartsman, M., R. Kikkeri, A. Shanzer y Z.I. Cabantchik: Non-transferrin-bound iron reaches mitochondria by a chelator-inaccessible mechanism: biological and clinical implications. Am. J. Physiol. Cell Physiol: 293(4), C1383-C1394 (2007). 
